\title{
artículos
}

\section{El conocimiento teórico de la materia de consulta en los programas de dos escuelas de bibliotecología en México}

\author{
Juan José Calva González* \\ Roberto Garduño Vera \\ Florencio Soriano Eslava
}

\begin{abstract}
RESUMEN
Investigar la existencia de las bases teóricas en la materia del Servicio de consulta es el objetivo de este trabajo. Los programas en los cuales se llevará a cabo esta actividad, son: el programa de la carrera de biblioteconomía a nivel licenciatura de la Escuela Nacional de Biblioteconomía y Archivonomía (ENBA) y el programa de la Escuela de Biblioteconomía de la Universidad Autónoma de San Luis Potosí (UASLP).

Para tal propósito se partió de lo que es y debe ser el servicio de consulta con base en los conocimientos teóricos y prácticos recibidos en el estudio y ejercicio de nuestra profesión y en los resultados del análisis de documentos de diversos teóricos que han escrito sobre el tema, donde se manifiesta la existencia de un cuerpo teórico desarrollado de los diferentes aspectos relacionados con este servicio.

Las teorías identificadas se enmarcaron para nuestro estudio dentro de grandes rubros, considerando como fundamentos de la teoría de consulta los siguientes: el bibliotecario, la comunicación, el servicio de consulta, el usuario y la función social del servicio de consulta, aspectos que son desarrollados a través de este documento.
\end{abstract}

\section{ABSTRACT}

The principal objetive of this study is to research the existence of theoretical bases in the area of Reference Service in the bachelor programs of Library Science in the Escuela Nacional de Biblioteconomía y Archivonomía (ENBA) and the Escuela de Biblioteconomía de la Universidad de San Luis Potosí (UASLP). The archive that end, I began with what is and what should be the service of Reference Service based upon theoretical and practical knowledge obtained in the study and exercise of our profession and in the results of the analysis of documents of diverse theoreticians who have written on the subject. There exists a developed body of theory written about the different aspects related to this service. The theories identified for our study can be classified into the following large categories considered fundamental for our topic: the librarian, communication, the service of Reference Service, the library user and the social function of the service of reference Service, aspects which are developed throughout this document.

\section{INTRODUCCIÓN}

$\mathrm{C}^{\text {lobjetivo de este trabajo es investigar }}$ Cla existencia de las bases teóricas en la materia de: Servicio de Consulta, que presentan los programas de carrera de biblioteconomía a nivel licenciatura en la Escuela Nacional de Biblioteconomía y
Archivonomía (ENBA) y en la Universidad Autónoma de San Luis Potosí. (UASLP).

\footnotetext{
* Los autores son, respectivamente: jefe del Departamento de Planeación de la Dirección General de Bibliotecas, investigador del Centro Universitario de Investigaciones Bibliotecológicas y jefe del Departamento de Selección y Adquisición de la Biblioteca Central, de la UNAM. Todos son participantes del Seminario de Educación Bibliotecológica de la Maestría de Bibliotecología de la UNAM.
} 
Para llevar a cabo esta investigación, se tomó en cuenta la observación generalizada tanto en el nivel de instituciones responsables de educación superior, como en instituciones oficiales. Existe en estas escuelas una evidente crisis en la educación superior que ha sido producto de un deterioro económico que requiere resolverse mediante cambios profundos en sus estructuras básicas. Es en el sector educativo, cuya función social es el desarrollo y mejoramiento de la sociedad, en donde debe replantearse las direcciones y objetivos educativos con objeto de brindar una solución inmediata y urgente en beneficio de la sociedad a la que sirve.

Una tarea importante que se han planteado para subsanar un poco todo esto, es la revisión de contenidos de los programas de estudio de las diferentes escuelas de educación superior en la República Mexicana con objeto de mejorar sustancialmente el nivel educativo.

Es compromiso para un grupo de profesionales de la biblioteconomía llevar a la práctica esa revisión de estudios y hacer un estudio comparativo de los contenidos de los programas de estudio de la asignatura Servicio de Consulta y analizar la existencia de las bases teóricas que la fundamentan.

La materia de Servicio de Consulta se encuentra sustentada por dos bases teóricas aunque éstas no se encuentran tratadas con profundidad en los contenidos de los programas de estudio de las dos escuelas a nivel licenciatura consideradas para este estudio: la Escuela Nacional de Biblioteconomía y Archivonomía y la Universidad Autónoma de San Luis Potosí.

Para este estudio se partió de la consideración de lo que es y debe ser el Servicio de Consulta con base en los conocimientos teóricos y prácticos recibidos en el estudio y ejercicio de nuestra profesión y se procedió a consultar a los teóricos sobre el tema; se detectó la existencia de un cuerpo teórico desarrollado en los diferentes aspectos relacionados con este servicio.

Estas teorías se enmarcaron para nuestro estudio, dentro de grandes rubros, considerando como los fundamentos de la teoría de consulta los siguientes: el bibliotecario, la comunicación, el Servicio de Consulta, el usuario y la función social del Servicio de Consulta, mismos que fueron objeto de identificación en los programas mencionados.

La metodología utilizada consistió en hacer la comparación de: la información representada en los contenidos, las actividades de aprendizaje y la bibliografía de ambos programas. Posteriormente se realizó un cuadro que contempló los tres aspectos considerados con objeto de poder analizar las coincidencias y las no coincidencias y en su caso las inferencias de la existencia de teorías consultadas en los programas señalados.

Después del análisis de los resultados obtenidos, se encontró una falta de precisión y profundidad teórica en el Servicio de Consulta contemplado en los programas de las escuelas mencionadas, por lo tanto se sugiere una revisión de los contenidos de dichos programas con base en nuestras disposiciones teóricas apoyadas en la bibliografía producto de nuestro análisis.

\section{SOBRE LA TEORÍA DEL SERVICIO DE CONSULTA}

\section{Antecedentes}

Abordar el tema sobre la teoría del Servicio de Consulta, hace necesario considerar que a finales del siglo XIX los bibliotecarios de esa época, empezaron a prestar mayor atención al usuario a través de un apoyo personalizado en la búsqueda de información de su interés. A esta forma de ofrecer el servicio le fue llamada "ayuda a los lectores" y "asistencia a los lectores".

Este concepto de asistencia al usuario perduró hasta 1876, en ese mismo año el norteamericano Samuel Swett Green, presentó la idea del trato personalizado y las relaciones entre el bibliotecario y el usuario. Este hecho es considerado por los historiadores que tratan el Servicio de Consulta como el punto de partida real hacia el desarrollo de una teoría sobre este tema.

Sin embargo la aceptación plena de esa idea se dio veinte años después (1896) bajo el término trabajo de consulta (reference work); término que reemplazó a los anteriormente citados.

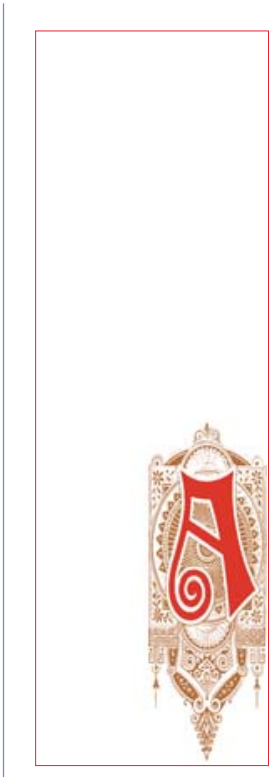

\section{Es el sector educativo donde deben replantearse las direcciones y objetivos para brindar una solución inmediata y urgente en beneficio de la sociedad a la que sirve}

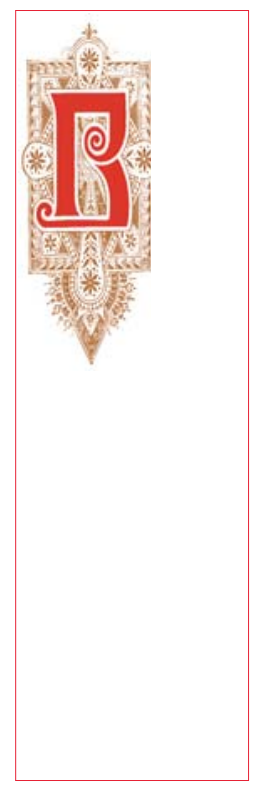


En esta época Samuel Swell Green continuó argumentando la necesidad de la ayuda personalizada y el conocimiento del catálogo por parte del usuario con el fin de que éste pudiera por sí mismo seleccionar el material de su interés. Estos hechos hacen notar el celo de este autor por lograr una mauro interacción entre el bibliotecario y el usuario, la preocupación de que este último logrará manejar herramientas bibliotecarias para auxiliar en la búsqueda de información.

Al concluir el siglo XIX y durante los primeros años del siglo XX, las bibliotecas más ricas y de mayor importancia, empezaron a contratar al bibliotecario de consulta, a identificar con precisión al departamento de consulta en el contexto administrativo de la biblioteca, a responder preguntas formuladas vía telefónica y por carta y a diferenciar el Servicio de Consulta por niveles de complejidad y áreas temáticas.

Entre los años 1917 y 1940, el desarrollo del Servicio de Consulta persistió con la intención de ayudar al usuario a llegar al material documental para apoyar su autoeducación y desarrollo cultural. Este aspecto, entre otros, originó la necesidad en el incremento de personal bibliotecario y en la creación de departamentos especializados del Servicio de Consulta. Otro aspecto importante que se dio en este periodo fue la delimitación de los niveles básicos en los que se debía fundamentar este servicio.

Después de 1940 se observó una preocupación creciente por conocer a profundidad las variables que se involucraban en el contexto del Servicio de Consulta, esto originó que diversos estudiosos hayan generado planteamientos de carácter teórico relacionados con este servicio.

Después de 1940 se observó una preocupación creciente por conocer a profundidad las variables que se involucraban en el contexto del Servicio de Consulta, esto originó que diversos estudiosos hayan generado planteamientos de carácter teórico relacionados con este servicio.

\section{Teoría del Servicio de Consulta}

Abordar un estudio sobre la teoría del Servicio de Consulta ha exigido investigar, identificar y analizar a diversos autores que han escrito sobre teoría filosófica en general y autores que han escrito sobre aspectos teóricos del Servicio de Consulta en particular, uno de los ejercicios fun- damentales fue el determinar con base en los autores analizados, la existencia de un cuerpo teórico del Servicio de Consulta. Con el fin de llegar a una respuesta válida fue necesario tomar en consideración los siguientes conceptos:

Mario Bunge afirma que "Una teoría o sistema deductivo es a su vez un conjunto de proposiciones ordenadas por la relación de deducibilidad. Así pues, en una teoría no existe ninguna proposición aislada, toda proposición es o una hipótesis o bien una conclusión. Con más precisión, una teoría es un sistema hipotético deductivo en el sentido que es expresable de tal manera, que toda fórmula que hay en el sistema constituye o bien una premisa inicial (hipótesis, axioma) o una consecuencia lógica de un conjunto inicial de suposiciones"

Por su parte José Ferrater sostiene que "Una teoría es un cuerpo coherente de conocimientos sobre un dominio de objetivos, cuando este cuerpo de conocimientos es formalizado, se origina una teoría axiomática. $^{2}$

Con base en estos conceptos, entre otros, se analizaron diversos documentos orientados a la teoría sobre el Servicio de Consulta a fin de identificar la existencia de proposiciones teóricas relacionadas con el tema abordado. Con apoyo en el análisis documental se decidió considerar como relevante la información siguiente ya que sería la base de mayor importancia para generar el marco teórico de este trabajo.

Con relación a la teoría sobre el Servicio de Consulta, hemos encontrado fundamentalmente dos corrientes. La primera es aquella donde algunos autores analizan la particularidad de variables específicas que se involucran en el Servicio de Consulta como un todo y consideran que una teoría al respecto debe involucrar el todo y no partes aisladas.

Los autores que conciben a la teoría de consulta como el todo, es decir, como un proceso global, consideran como razón fundamental el proceso mismo de referencia en donde la estructura interpretativa puede aplicarse tan válidamente en el principio como al final, esto es, que se involucra desde la generación de la pregunta a la aplicación de la respuesta, considerando así los diferentes procesos de referencia y que corresponden al ¿qué? Y al ¿cómo? Se dan estos procesos en un problema planteado y no al ¿para qué? que es el planteamiento principal del problema.

Del planteamiento principal de cómo es que el Servicio de Consulta se llega a dictaminar una teoría general que incluya todas las teorías definidas llamadas subteorías por algunos autores como básicas en el Servicio de Consulta.

Pudimos apreciar que el Servicio de Consulta se distingue fundamentalmente de otros servicios bibliotecarios, por el alto nivel de interacción personalizada entre bibliotecarios y usuarios, interacción que se da en el proceso de identificar una necesidad de información y la obtención de la misma.

Estructurar un cuerpo teórico del Servicio de Consulta, ha sido una preocupación de diversos autores, quienes han analizado: la evolución histórica, las formas de proporcionar este servicio, los sujetos y objetos que modifican el servicio, y las interacciones bibliotecario-usuario-información.

Samuel Rothstein (1955) por su parte examinó las posibilidades de ayuda que en el Servicio de Consulta se le puede proporcionar al usuario, con base en su idea "ayuda es una palabra que abarca una enorme extensión y variedad de actividades". Postuló los niveles del Servicio de Consulta como servicio mínimo, servicio medio y servicio máximo. Se puede decir que Rothstein fue influenciado por Wyer pues siguió su línea en postular los niveles del servicio.

Principalmente, con base en estos autores se generó lo que en la actualidad se conoce como teorías conservadora, moderada y liberal del Servicio de Consulta, mismas que se plantean en los siguientes niveles:

Nivel conservador. Se da una interacción directa bibliotecario-usuario, sin fuentes documentales.

Nivel moderado. Se da cuando se ofrece en forma ocasional un servicio directo con el usuario, más el uso de fuentes documentales, consultadas por el bibliotecario o por el usuario. 
Nivel liberal. Se da cuando se utilizan patrones de búsqueda, los recursos documentales de la biblioteca y los de otras bibliotecas si es necesario.

Estos mismos conceptos son considerados por Ruch (19875) quien afirma que debido a que los bibliotecarios están íntimamente involucrados con los libros, todos los conceptos para una teoría del Servicio de Consulta deben ser derivados deductivamente, con base en esos conceptos.

Para Kenneth Whittaker (1977) una teoría sobre el Servicio de Consulta consiste en la suma de información derivada en forma eficaz de las fuentes documentales, para cubrir una necesidad de información.

Por otra parte Alan Rees (1967) al preguntar ¿Cuál es la naturaleza fundamental del Servicio de Consulta? Incorpora la suma total de variables involucradas en el trabajo de consulta, por un intermediario que es el bibliotecario de consulta, esto incluye el manejo psicológico del usuario, el empleo adecuado de las fuentes documentales y la percepción de necesidades del usuario, que son partes esenciales del trabajo de consulta.

Se puede notar que este autor incorpora el manejo de los términos: intermediario, manejo psicológico del usuario y percepción de necesidades, como aspectos que permiten orientar una teoría del Servicio de Consulta al tomar como básica la disciplina psicológica.

Otro aspecto importante emanado de las lecturas y que tiene que ver con la teoría del Servicio de consulta, es su función social. El propósito social responde a principios universales de servicio al considerar básicamente a la democracia que se ejerce en los mecanismos de servicio, educación y recreación.

En cuanto a principios éticos, Samuel Rothstein (1977) señala que existe un servicio hacia la comunidad que no se ha analizado suficientemente en cuanto a los fundamentos de las acciones de los bibliotecarios, al buscar una definición apropiada a la ética del servicio, agrega que: "ética es ofrecer un servicio ilimitado".
La American Library Association (ALA) sostiene cinco principios éticos del servicio, mismos que son aplicables al de consulta, éstos son:

1. La información que se provee al usuario en respuesta a cualquier pregunta, debe ser lo más exacta que sea posible. El tipo de pregunta y el estatus del usuario, no deben ser considerados.

2. Las filosofías y actitudes personales, no se deben reflejar en la ejecución del servicio o en la extensión y exactitud de la información provista.

3. La información contactada con el usuario, en todo caso, las referencias o direcciones, deben ser tratadas con completa confidencialidad.

4. Todas las reglas y prácticas con respecto a la disponibilidad y uso de información, deben ser administradas imparcialmente. Todas las reglas y prácticas, deben ser codificadas y puestas a disposición del usuario en forma escrita.

5. Ningún aspecto de característica financiera, podrá acarrear resultados benéficos debido a que el bibliotecario especialista en información, juega un papel de representante de la biblioteca y su comportamiento con el usuario debe ser ejemplar.

Por lo que respecta al proceso de la comunicación en el Servicio de Consulta, se puede decir que el interés por su estudio se originó en los inicios del siglo XX, cuando se empezaron a perfilar proposiciones teóricas, que posteriormente permitieron estructurar teorías de la comunicación orientadas al Servicio de Consulta.

Weaver (1949) influenciado por la teoría de Shanon referida a la ingeniería en la comunicación, considera los efectos en cuanto a la conducta del receptor de la solicitud de información. En esta teoría se consideran como variables básicas las siguientes: emisor, receptor (bibliotecario)-mensaje-obtención del producto.

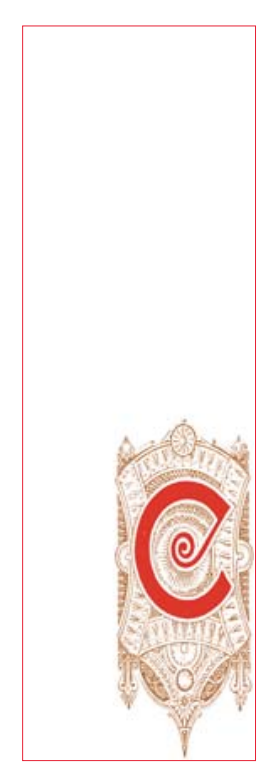

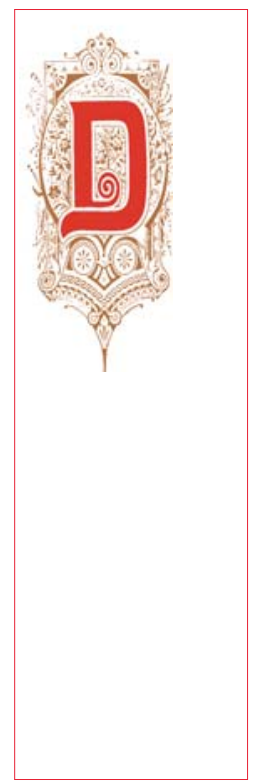


Gothberger en esta época afirma al respecto que hacia fines del siglo XX, la comunicación interpersonal debe verse como una de las bases del trabajo de consulta, esa comunicación debe estar basada en la multidisciplina al considerar ciencias como la Psicología, la Psiquiatría, la Antropología, la Lingüística y la Semiótica, entre otras.

Los pioneros principales de la teoría en comunicación interpersonal son Roger, Bales, Moreno y Maslow, su aportación se ha basado en el esclarecimiento de la comunicación interpersonal que se da de persona a persona y en grupos pequeños, considerando como base la comunicación.

Los estudios de estos autores, han permitido rescatar fundamentos teóricos que recientemente se han aplicado a la comunicación interpersonal en el contexto del Servicio de Consulta.

Se afirma que uno de los mayores problemas de la comunicación en el Servicio de consulta, se presenta en la negociación de la pregunta. Ese aspecto ocasiona por tanto, consecuencias negativas que son acarreadas hasta la entrega de la información.

James Retting (1878) afirma que un modelo teórico y definitorio de los procesos de consulta se deben basar en la comunicación interpersonal. Su modelo de comunicación interpersonal involucra las variables: usuario, mensaje, destinatario del mensaje (bibliotecario).

Por su parte, Vavrek (1968?) señala que las operaciones del especialista de consulta, deben estar orientadas hacia la comprensión de lo comunicado, para conectarlas a los recursos de la biblioteca, por lo que el bibliotecario de consulta, debe por lo menos tomar en cuenta lo siguiente:

1. Considerar un diálogo profundo con el usuario, con base en un modelo.

2. Ser capaz de entender los diferentes caminos para llegar a la información a través de un modelo.

3. Entender los aspectos psicológicos y pragmáticos relacionados a la pregunta.

\section{Tener conocimiento profundo sobre el} papel de la biblioteca, en el proceso de la comunicación.

Existe la corriente que afirma que la teoría de la información constituye la herramienta fundamental de la comunicación, en ella se involucran; gente, equipo de ingeniería, telégrafo, teléfono y radio, entre otros.

Sin embargo la teoría de la comunicación sostiene dos orientaciones básicas: la comunicación interpersonal y la comunicación en la transmisión de información a través de canales electrónicos. Se han suscitado polémicas que sostienen que la comunicación sólo debe ser interpersonal ya que exige la existencia de sujetos (usuario-bibliotecario), por lo que la comunicación de la información con base en herramientas electrónicas sólo puede considerarse transmisión de información y no comunicación.

Se puede apreciar que la generación de teorías sobre la comunicación en el Servicio de Consulta, se fundamentan en la multidisciplina, aspecto que enriquece el cuerpo teórico relacionado con este rubro.

Con relación al usuario, podemos señalar que la biblioteca, como organismo, debe satisfacer las necesidades de información de sus usuarios, esto se realiza a través del conjunto de servicios que ofrece la biblioteca, principalmente a través del Servicio de Consulta, el cual es el intermediario entre la información y el usuario.

El usuario en el Servicio de Consulta es un factor de vital importancia ya que precisamente es a él al que se le brinda este servicio.

Con base en un enfoque psicológico, podemos situar al usuario de la biblioteca, siguiendo la jerarquía de necesidades de Abraham Maslow; el cual menciona que el ser humano está movido o motivado a actuar, o a comportarse de diversas maneras por una serie de necesidades que se presentan en él. De esta forma el usuario de la biblioteca, como persona, presenta también una serie de necesidades, de las cuales satisface principalmente las básicas que, siguiendo la jerarquía de necesidades de Maslow, son:

- Necesidades primarias o fisiológicas
- Necesidades de seguridad

- Necesidades sociales

Las necesidades de información que presenta el usuario de la biblioteca se encuentra en los niveles más altos, es decir con las necesidades de estima y con las necesidades de autorrealización.

La biblioteca para lograr satisfacer las necesidades de información del usuario, se valdrá de todas las actividades profesionales que realiza, principalmente, la del Servicio de Consulta.

Pero las necesidades de información del usuario varían entre unos y otros, es decir, esto va a depender del nivel de estudios, actividad que realiza y la propia motivación interna del usuario, lo que conducirá a brindar un nivel de servicio (conservador, medio o liberal dependiendo del tipo de usuario y tipo de biblioteca.

Por tanto el Servicio de Consulta debe satisfacer las necesidades de información de cualquier tipo de usuario.

El Servicio de Consulta no sólo debe satisfacer las necesidades de información del usuario, sino también estimular o motivar la autosatisfacción de las necesidades de información del propio usuario, esto se puede lograr a través de una instrucción de usuarios. Esta actividad es de vital importancia dentro de la biblioteca, puesto que da otro giro a las actividades de la misma ampliando su atención a los usuarios.

Proposiciones teóricas de apoyo al análisis de los programas de la materia de servicio de consulta

Las proposiciones teóricas filosóficas que aquí se presentan se apoyan en los autores que fueron objeto de análisis. Autores que se han preocupado por aspectos teóricos del Servicio de Consulta. Estas proposiciones son la base para apoyar el análisis de los programas de la Escuela Nacional de Biblioteconomía y Archivonomía y de la Universidad de San Luis Potosí, referidos a la materia sobre el Servicio de Consulta, tema que se aborda en el siguiente apartado.

Estas proposiciones teóricas se agruparon por áreas, con el fin de facilitar su interpretación. 


\section{El bibliotecario}

- Ser especialista en el Servicio de Consulta, implica agrupar todos aquellos elementos que existen entre el lector y la información

- El bibliotecario de consulta profesional, debe estar involucrado en los quehaceres de la biblioteca y por ende de la información.

- La imagen y estatus del bibliotecario están en relación con su actitud como bibliotecario del Servicio de Consulta.

- A mayor conocimiento del acervo, mayor utilidad del mismo.

- El Servicio de Consulta, es una actividad fundamentalmente académica.

\section{El usuario}

- La presentación de una necesidad de información satisfacción de la misma.

- La satisfacción de necesidades de información del usuario está en función de la actividad profesional de la biblioteca.

- El tipo de usuario determina el nivel del servicio.

- El Servicio de Consulta lleva implícita una relación interpersonal, bibliotecario-usuario.

- La estimulación e la autosatisfacción de necesidades de información del propio usuario, están en relación con la instrucción de usuarios que ofrezca el Servicio de Consulta.

\section{El Área de Consulta}

- La infraestructura de recursos humanos, financieros e instalaciones inciden en la calidad de los servicios de consulta.

- Los procedimientos administrativos entorpecen o agilizan el Servicio de Consulta.

\section{La Comunicación}

- El Servicio de consulta lleva implícita una relación interpersonal bibliotecario-usuario.

- Un mayor acceso a la información, está en función de la utilización de medios masivos (radio, prensa, televisión, etcétera) de comunicación, en el Servicio de Consulta.

- La base de la comunicación en el Servicio de consulta, está en relación con el transmisor y el receptor.

- La retroalimentación en la comunicación, provee la información necesaria para crear las bases de control y adaptación del mensaje.

- El bibliotecario de consulta es el receptor y decodificador del mensaje inicial.

- La pobreza del mensaje (comunicador-receptor) estará en relación directa con la pertinencia de la información obtenida.

- A través del proceso de comunicación, el bibliotecario debe determinar las combinaciones que procedan al mensaje, considerando pertinencia de combinación.

- La retroalimentación continua por parte del usuario se reflejará en términos de satisfacción en el servicio.

- El servicio de Consulta es el emisor y receptor de la información.

\section{La función social del Servicio de Consulta}

- El Servicio de Consulta es el medio para que la biblioteca cumpla su función social respecto a la difusión de la cultura.

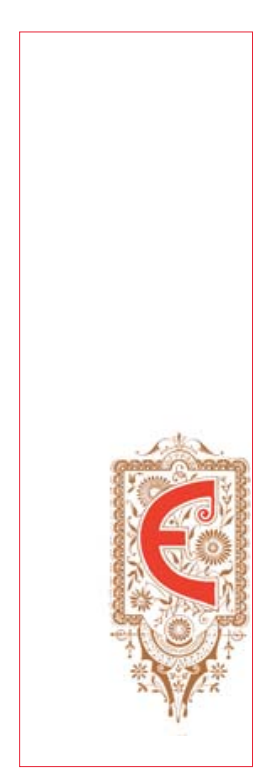

\section{El Servicio de Consulta es el medio para que la biblioteca cumpla su función social respecto a la difusión de la cultura}

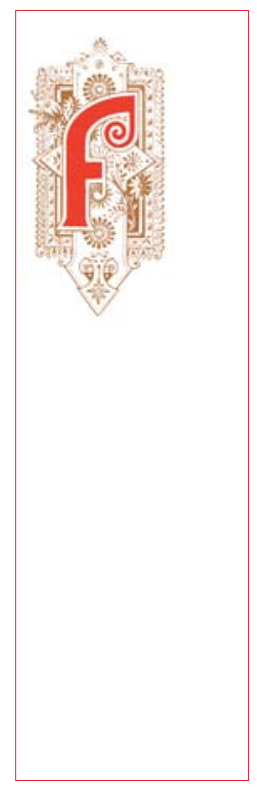




\section{LA TEORÍA DEL SERVICIO DE CONSULTA EN LOS PROGRAMAS IMPARTIDOS EN LA ESCUELA NACIONAL DE BIBLIOTECONO- MÍA Y ARCHIVONOMÍA Y EN LA UNIVERSIDAD AUTÓNOMA DE SAN LUIS POTOSÍ}

\section{Sobre los programas de la materia de consulta}

A través del tiempo, se han observado que el servicio de consulta es uno de los servicios bibliotecológicos de mayor importancia académica, el contacto directo con el usuario para apoyarlo en sus búsquedas documentales, requiere de un alto grado de preparación académica, habilidad en la comunicación con el usuario, conocimiento de las fuentes documentales de apoyo y de cultura general, entre otros aspectos

Lo mencionado anteriormente es una de las preocupaciones de las escuelas señaladas, por lo tanto, los programas referidos al servicio de consulta procuran cubrir las diversas variables involucradas en este servicio.

Es importante hacer notar que los programas analizados fueron los que se manejan en forma oficial en las escuelas señaladas. Se tomó esta opción debido a que existen, además de los programas oficiales, los que utiliza cada maestro que imparte la materia, se observó que estos programas no coinciden en los diversos contenidos con los oficiales.

El análisis de los programas de las escuelas referidas, relacionados con la materia de consulta, tuvo como propósito identificar si además de lo señalado, esos programas contemplaban la enseñanza de fundamentos teóricos relacionados con el servicio de consulta. Este propósito,, exigió definir un método que permitiera la yuxtaposición de constantes y variables para realizar la intención señalada.

El método utilizado fue la comparación, ya que el manejo de analogías a través de la misma, permiten visualizar con facilidad el fenómeno que se requiere destacar, para posteriormente inferir del mismo opiniones de carácter crítico.

Las variables definidas para la estructura del cuadro fueron:
- Contenidos temáticos por unidad de cada programa

- Proposiciones teóricas

- Práctica

- Técnicas de enseñanza

- Bibliografía de apoyo

Cada uno de estos rubros fue objeto de análisis y discusión, aspectos que enriquecieron el análisis de los mismos y facilitaron la aplicación del método comparativo, específicamente yuxtaponiendo las proposiciones teóricas con los contenidos de cada programa, buscando la identificación de carácter teórico.

En algunos casos fue necesario inferir de los objetivos de los programas algunos aspectos que se orientaran a la enseñanza teórica y que no estuvieran especificados en los contenidos de estos programas.

\section{Análisis comparado de los programas de la materia del Servicio de Consulta}

En el presente apartado se tratan las variables involucradas en el análisis de los programas, los cuales son: contenido de los programas, proposiciones teóricas, área práctica, técnicas de enseñanza y bibliografía. El resultado del análisis es el siguiente:

\section{UNIDAD 1}

El departamento de consulta

En el programa planteado por la Escuela Nacional de Biblioteconomía y Archivonomía (ENBA), dicha unidad en el inciso "b" titulado "los elementos que integran el departamento de consulta", coincide con el punto 4 de la unidad del programa de San Luis Potosí denominado características (del Servicio de Consulta).

El inciso "d" del programa de la ENBA que contempla las funciones del Servicio de Consulta, está considerado en el programa de San Luis Potosí en el inciso "a" de la unidad III, y se refiere a las funciones del departamento de consulta. Esta unidad fue necesario relacionarla con a unidad 1 del programa de la ENBA en virtud de que el punto "a" el Servicio de Consulta, es coincidente con el inciso "d" del programa de la ENBA, que se refiere a "funciones del Servicio de Consulta".
Ahora bien, los puntos no concordantes entre ambos programas con los siguientes: La ENBA trata en el inciso "a" la ubicación dentro de la biblioteca del departamento de consulta y en el inciso "c" su relación con otros departamentos.

En cuanto a los puntos del programa de San Luis Potosí se tratan los siguientes: 1. su historia, 2. definición y 3 . objetivos del Servicio de Consulta; se intuye que todos ellos se encuentran contemplados en relación con el departamento de consulta, del programa de la ENBA.

\section{Proposiciones Teóricas}

Las proposiciones teóricas referentes al Servicio de consulta citadas en el apartado anterior, concuerdan con la unidad I el departamento de consulta, inciso "d" funciones del Servicio de Consulta, de la ENBA y la unidad III organización del departamento de consulta, inciso "a" funciones del departamento de consulta, de San Luis Potosí.

\section{Área Práctica}

En cuanto a este rubro, no hay ninguna práctica en la unidad I de ambos programas.

\section{Técnicas de Enseñanza}

Las coincidencias que se presentan en la unidad I de ambos programas son las referentes a la utilización de discusión dirigida e interrogatorio, y no existe coincidencia con la elaboración de cuadros sinópticos y ensayos, utilizados únicamente en la ENBA.

\section{Bibliografía}

Basilio Romero, Concepción. Metodología de consulta.

Este trabajo está enfocado hacia las funciones y técnicas del Servicio de Consulta. Toma en consideración diversos aspectos involucrados en este servicio, dándoles una orientación eminentemente práctica.

Cheny Frances Neel. Fundamental reference sources. Chicago: American Library Association, 1971. 318 p. 


\begin{tabular}{|c|c|c|c|c|c|c|c|}
\hline$E N B A$ & \multicolumn{2}{|r|}{ SLP } & $\left|\begin{array}{l}\text { PRAC } \\
\text { TICAS }\end{array}\right|$ & $E N B A$ & $S L P$ & $E N B A$ & $S L P$ \\
\hline UNIDAD I & UNIDAD I & PROPOSICIONES TEORICAS & & $\begin{array}{l}\text { TECNI } \\
\text { ENSE }\end{array}$ & $\begin{array}{l}\text { AAS DE } \\
\text { IANZA }\end{array}$ & \multicolumn{2}{|c|}{ BIBLIOGRAFIA } \\
\hline $\begin{array}{l}\text { Departamento } \\
\text { de consulta } \\
\text { a.- Ubicación } \\
\text { dentro de la } \\
\text { biblioteca } \\
\text { b.- Elementos } \\
\text { que integran el } \\
\text { departamento } \\
\text { c.- Relaciones } \\
\text { con otros } \\
\text { departamentos }\end{array}$ & $\begin{array}{l}\text { A. El servicio de } \\
\text { consulta } \\
\text { 1.- Historia } \\
\text { 2.- Definición } \\
\text { 3.- Objetivo } \\
\rightarrow \text { 4.Características }\end{array}$ & . & & $\begin{array}{l}\text { Discusión } \\
\text { dirigida } \\
\text { Interro- } \\
\text { gatorio } \\
\text { Cuadros } \\
\text { sinópticos } \\
\text { Ensayos }\end{array}$ & $\begin{array}{l}\text { Discusión } \\
\text { dirigida } \\
\text { Interrogato } \\
\text { rio }\end{array}$ & $\begin{array}{l}\text { Basilio C. } \\
\text { Metodología de } \\
\text { consulta. } \\
\text { Ciencia } \\
\text { Bibliotecaria } 2 \\
\text { (1) : 29-32. 1978 } \\
\text { Wheeler, J.L. } \\
\text { Administración } \\
\text { práctica de } \\
\text { bibliotecas } \\
\text { públicas. } \\
\text { México, F.C. E., } \\
1970 \text { pp. 328- } \\
350 \\
\text { Lancaster, F. } \\
\text { Evaluación y } \\
\text { medición de los } \\
\text { servicios } \\
\text { bibliotecarios. } \\
\text { México, UNAM, } \\
\text { 1977. Pp. 85-157 }\end{array}$ & $\begin{array}{l}\text { Cheney, F. N. y } \\
\text { Wiley J. M. } \\
\text { Fundamental } \\
\text { reference } \\
\text { sources. } 2 \text { nd } \\
\text { ed. Chicago, } \\
\text { ALA, 1980. pp. 6- } \\
8 \\
\text { Galvin, T. J. } \\
\text { "Refrence } \\
\text { services and } \\
\text { libraries". En: } \\
\text { Encyclopedia of } \\
\text { library and } \\
\text { information } \\
\text { science New } \\
\text { York, Marcel } \\
\text { Dekker, 1972. v., } \\
25 \text { pp. 210-226. }\end{array}$ \\
\hline $\begin{array}{l}\text { d.- Funciones- } \\
\text { del servicio de } \\
\text { consulta }\end{array}$ & $\begin{array}{l}\text { UNIDAD III } \\
\text { Organización } \\
\text { del } \\
\text { departamento } \\
\text { de consulta. } \\
\text { a.-Funciones del } \\
\text { departamento } \\
\text { de consulta }\end{array}$ & $\begin{array}{l}\text { SERVICIO DE CONSULTA } \\
\text { - La infraestructura de } \\
\text { recursos humanos, } \\
\text { financieros e instalaciones, } \\
\text { inciden en la calidad de los } \\
\text { servicios de consulta } \\
\text { - Los procedimientos } \\
\text { administrativos entorpecen o } \\
\text { agilizan el servicio de consulta }\end{array}$ & & & & & $\begin{array}{l}\text { Barberena } \\
\text { Blazquez, E. "EI } \\
\text { servicio de } \\
\text { consulta" - } \\
\text { Bibliotecas y } \\
\text { archivos. (1): } \\
29-35.1967 . \\
\text { Gould, C. N. y } \\
\text { Wolfe, I. C. How } \\
\text { to organize and } \\
\text { maintain the } \\
\text { library } \\
\text { picture/pamphlet } \\
\text { file. New York } \\
\text { Oceano. 1968. } \\
\text { pp. 1-7, 21-25, } \\
84-94 \\
\text { Galvin, T. J. } \\
\text { "Reference } \\
\text { services and } \\
\text { libraries." En: } \\
\text { Encyclopedia of } \\
\text { libabry and } \\
\text { information } \\
\text { science. New } \\
\text { York, Marcel } \\
\text { Dekker, 1972. v. } \\
\text { 25, pp. 210-226 }\end{array}$ \\
\hline $\begin{array}{l}\text { UNIDAD II } \\
\text { El bibliotecario } \\
\text { de consulta } \\
\text { a.- Preparación } \\
\text { b.- Cualidades }\end{array}$ & & $\begin{array}{l}\text { EL BIBLIOTECARIO DE } \\
\text { CONSULTA } \\
\text { - Ser especialista en el } \\
\text { servicio de consulta, implica } \\
\text { agrupar todos aquellos } \\
\text { elementos que existenentre } \\
\text { el lector y la información. } \\
\text { - El bibliotecario de consulta } \\
\text { profesional debe estar } \\
\text { involucrado en los } \\
\text { quehaceres de la biblioteca y } \\
\text { por ende de la información. } \\
\text { - La imagen y el estatus del } \\
\text { bibliotecario están en relación } \\
\text { con su actitud como } \\
\text { bibliotecario de consulta. } \\
\text { - A mayor conocimiento del } \\
\text { acervo, mayor utilidad del } \\
\text { mismo. } \\
\text { - El servicio de consulta es } \\
\text { una actividad fundamental- } \\
\text { mente académica. }\end{array}$ & & $\begin{array}{l}\text { Investiga- } \\
\text { ción } \\
\text { individual } \\
\text { Cuadros } \\
\text { sinópticos }\end{array}$ & & $\begin{array}{l}\text { Basilio, C. } \\
\text { "Metodología } \\
\text { de consulta" En: } \\
\text { Ciencia } \\
\text { bibliotecaria } 2 \\
\text { (1): } 29,36-37 \\
1978 . \\
\text { Wheeler, J. L. } \\
\text { Adminstración } \\
\text { práctica de } \\
\text { bibliotecas } \\
\text { públicas. } \\
\text { México, F.C.E. } \\
1970 \text { pp. 334- } \\
340 \\
\text { Petru, W. } \\
\text { Técnicas del } \\
\text { bibliotecario. } \\
\text { México, Pax- } \\
\text { Mex, 1973 }\end{array}$ & \\
\hline
\end{tabular}




\begin{tabular}{|c|c|c|c|c|c|c|c|}
\hline$E N B A$ & \multicolumn{2}{|c|}{$S L P$} & $\begin{array}{c}\text { PRAQ } \\
\text { TI } \\
\text { CAS }\end{array}$ & \multicolumn{2}{|c|}{$\begin{array}{l}\text { TECNICAS DE } \\
\text { ENSENANZA }\end{array}$} & \multicolumn{2}{|c|}{ BIBLIOGRAFIA } \\
\hline UNIDAD III & UNIDAD IV & & & ENBA & SLP & ENBA & SLP \\
\hline $\begin{array}{l}\text { Las obras de } \\
\text { consulta } \\
\text { a.- Definición } \\
\text { b.- Tipos } \\
\text { 1.- Diccionarios } \\
\text { 2.- Enciclopedias } \\
\text { 3.- Anuarios } \\
\text { 4.- Bibliografías } \\
\text { 5.- Indices } \\
\text { 6.- Directorios } \\
\text { 7.- Atlas } \\
\text { 8.- Otros }\end{array}$ & \begin{tabular}{|l|} 
Evaluación del material de \\
consulta \\
a.- Obras de consulta \\
1. Definición \\
b.-Material específico de \\
consulta \\
2.- Diccionarios \\
a.- Definición \\
b.- Características \\
1.- Enciclopedias \\
a.- Definición \\
b.- Características \\
5.- Almanaques, Anuarios, \\
Directorios \\
a.- Definición \\
b.- Características \\
4.- Bibliografías \\
a.- Definición \\
b.- Características \\
3.- Indices \\
a.- Definición \\
b.- Características \\
5.- Almanaques, Anuarios, \\
Directorios \\
a.- Definición \\
b.- Características \\
6.- Resúmenes \\
a.- Definición \\
b.- Características \\
7.- Biografías \\
a.- Definición \\
b.- Características \\
8.- Publicaciones oficiales \\
a.- Definición \\
b.- Características \\
9.- Microformatos \\
a.-- Definición \\
b.- Características \\
UNIDAD III \\
b.- Catálogos \\
1.- Editoriales \\
2.- Servicios al público \\
3.- Colectivos \\
4.- Archivo vertical \\
UNIDAD IV \\
Objetivos particulares \\
1.- Definir en qué consisten \\
las obras de consulta \\
2.- Analizar el tipo de \\
material utilizado en \\
consulta \\
3.- Evaluar las obras de \\
consulta \\
\end{tabular} & 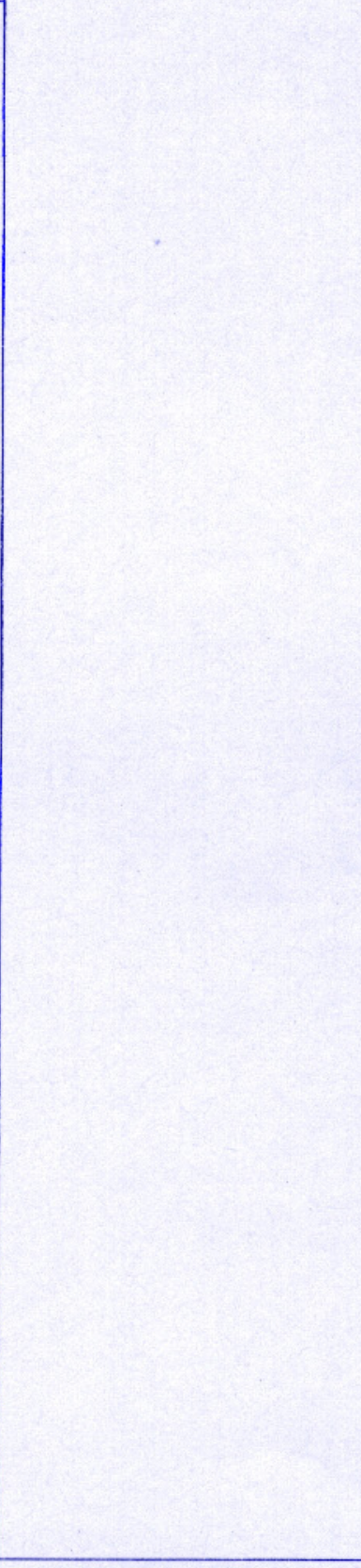 & & $\begin{array}{l}\begin{array}{l}\text { Luvia de } \\
\text { ideas }\end{array} \\
\text { Investigación } \\
\text { individual } \\
\text { Elaboración } \\
\text { de ficha bi- } \\
\text { bliográficas } \\
\text { para } \\
\text { determinar } \\
\text { su arreglo y } \\
\text { contenido }\end{array}$ & $\begin{array}{l}\text { Discu- } \\
\text { sión } \\
\text { dirigida } \\
\text { Interro- } \\
\text { gatorio } \\
\text { Demos } \\
\text { tración }\end{array}$ & $\begin{array}{l}\text { Katz, W. } \\
\text { Introdution } \\
\text { to reference } \\
\text { work. 3rd. } \\
\text { ed. New } \\
\text { York, } \\
\text { McGraw } \\
\text { Hill. 1978. } \\
\text { pp. 13/15 } \\
\text { Perales, A. } \\
\text { Las obras } \\
\text { de consulta. } \\
\text { México, } \\
\text { UNAM, } 1962 \\
\\
\text { Sabor, } \\
\text { Josefa E. } \\
\text { Manual de } \\
\text { fuentes de } \\
\text { información. } \\
\text { 3ed. } \\
\text { Buenos } \\
\text { Aires, } \\
\text { Marymar, } \\
\text { 1978 }\end{array}$ & $\begin{array}{l}\text { Shores, L. y } \\
\text { Krzys, R. } \\
\text { "Reference } \\
\text { books". En: } \\
\text { Encyciopedia } \\
\text { of library } \\
\text { and } \\
\text { information } \\
\text { science. } \\
\text { New York, } \\
\text { Marcel } \\
\text { Dekkeer, } \\
\text { 1972. v.25 } \\
\text { pp. 152-197 }\end{array}$ \\
\hline & $\begin{array}{l}\text { UNIDAD II } \\
\text { Información que } \\
\text { proporciona el servicio de } \\
\text { consulta } \\
\text { a.- Tipos de preguntas } \\
\text { 1.- Orientación } \\
\text { 2.- Respuesta concreta y } \\
\text { rápida } \\
\text { 3.- Investigación biblio- } \\
\text { gráfica } \\
\text { b.- Entrevista bibliotecario } \\
\text { usuario } \\
\text { c.- Características de una } \\
\text { respuesta adecuada }\end{array}$ & $\begin{array}{l}\text { LA COMUNICACION } \\
\text { - El servicio de consulta } \\
\text { lleva implícita una relación } \\
\text { interpersonal. } \\
\text { - Un mayor acceso a la } \\
\text { información, está en función } \\
\text { de la utilización de medios } \\
\text { masivos de comunicación, } \\
\text { incluyendo las } \\
\text { telecomunicaciones, en el } \\
\text { servicio de consulta. } \\
\text { - La base de al } \\
\text { comunicación en el servicio } \\
\text { de consulta, está en relación } \\
\text { con el transmisor y el } \\
\text { receptor. }\end{array}$ & & & $\begin{array}{l}\text { Discu- } \\
\text { sión } \\
\text { dirigida } \\
\text { Interro- } \\
\text { gatorio } \\
\text { Dramati } \\
\text { zación }\end{array}$ & & $\begin{array}{l}\text { Foskett, D. } \\
\text { J. } \\
\text { Information } \\
\text { services in } \\
\text { libraries. } \\
\text { London, } \\
\text { Crosby } \\
\text { Lockwood, } \\
1967, \text { pp. } 79- \\
92 \\
\text { Katz, W. A. } \\
\text { Introduction } \\
\text { to reference } \\
\text { work. 3rd } \\
\text { ed., New } \\
\text { York, } \\
\text { McGraw } \\
\text { Hill, } 1978 \\
\text { v. } 2 \text { pp. } 61 \text { - } \\
79,81-119\end{array}$ \\
\hline
\end{tabular}




\begin{tabular}{|c|c|c|c|c|c|c|c|}
\hline$E N B A$ & & SLP & $\begin{array}{c}\text { PRACTID } \\
\text { AS }\end{array}$ & $\begin{array}{r}\text { TECl } \\
I \\
\text { ENS! } \\
?\end{array}$ & $\begin{array}{l}I C A S \\
E \\
N A N \\
A\end{array}$ & $B I B L$ & IOGRAFIA \\
\hline & & & & ENBA & SLP & ENBA & SLP \\
\hline & & $\begin{array}{l}\text { LA COMUNICACION } \\
\text { - La retroalimentación en la comunicación provee } \\
\text { la información necesaria para crear las bases de } \\
\text { control y adaptación del mensaje. } \\
\text { - El bibliotecario de consulta es el receptor y } \\
\text { decodificador del mensaje inicial. } \\
\text { - A traves del proceso de comunicación, el } \\
\text { bibliotecario debe determinar las comunicaciones } \\
\text { que procedan al mensaje considerado pertinencia } \\
\text { de combinación } \\
\text { - La pobreza del mensaje (comunicador-receptor) } \\
\text { estará en relación directa con la pertinencia de la } \\
\text { información obtenida. } \\
\text { - La retroalimentación continua por parte del } \\
\text { usuario se reflejará en términos de satisfacción con } \\
\text { el servicio. } \\
\text { - El servicio de consulta es el emisor y receptor de } \\
\text { la información } \\
\text { EIICA } \\
\text { 1.- La información que se provee al usuario en } \\
\text { respuesta a cualquier pregunta, debe ser lo más } \\
\text { exacto que sea posible. El titoo de pregunta y el } \\
\text { estatus del usuario no deben ser considerados. } \\
\text { 2.- Las filosofías y actitudes personales, no se } \\
\text { deben reflejar en la ejecución del servicio o en la } \\
\text { extensión y exactitud de la información provista. } \\
\text { 3.- La información contactada en el usuario, en } \\
\text { todo caso, las referencias o direcciones, deben ser } \\
\text { tratadas con completa confidencialidad. } \\
\text { 4.- Todas las reglas y prácticas con respecto a la } \\
\text { disponibilidad y uso de información, deben ser } \\
\text { administradas imparcialmente. Todas las reglas y } \\
\text { prácticas deben ser codificadas y puestas a } \\
\text { disposición del usuario en forma escrita } \\
\text { 5.- Ningún aspecto de carácter financiero podrá } \\
\text { acarrear resultados benéficos debido a que el } \\
\text { bibliotecario especialista en información juega un } \\
\text { papel de representante en la biblioteca y su } \\
\text { comportamiento con el usuario debe ser ejemplar. }\end{array}$ & & & & & $\begin{array}{l}\text { lat } \\
\\
\text { Teller, R. } \\
\text { "Ethical } \\
\text { consideration } \\
\text { in the } \\
\text { question } \\
\text { negotiation } \\
\text { cycle." En: } \\
\text { The reference } \\
\text { librarian 10(4): } \\
\text { 133-141. 1982 }\end{array}$ \\
\hline & $\begin{array}{l}\text { UNIDAD IV } \\
\text { Búsqueda de información } \\
\text { a.- Descubrir el material y } \\
\text { encabezamiento utilizado } \\
\text { para encontrar la respuesta. } \\
\text { b.- Proporcionar como } \\
\text { respuesta las preguntas } \\
\text { 1.- La signatura topo- } \\
\text { gráfica } \\
\text { 2.- La ficha bibliográfica } \\
\text { 3.- Biblioteca o archivo } \\
\text { donde se localice la } \\
\text { información }\end{array}$ & & & & $\begin{array}{l}\text { Demos } \\
\text { tración }\end{array}$ & & \\
\hline & & $\begin{array}{l}\text { FUNCION SOCIAL } \\
\text {-El servicio de consulta es el medio para que la } \\
\text { biblioteca cumpla cońs'su función social de la } \\
\text { difusión social del conocimiento. } \\
\text { EL USUARIO } \\
\text { - El tipo de usuario determina el nivel del servicio } \\
\text { - La satisfacción de la necesidad de información, } \\
\text { está en función de las actividades profesionales } \\
\text { que se realizan en la biblioteca. } \\
\text { - La estimulación de la autosatisfacción de las } \\
\text { necesidades de información por el propio usuario, } \\
\text { está en relación de la instrucción de usuarios que } \\
\text { se proporcione en el servicio de consulta. } \\
\text { - A presentación de una necesidad de información, } \\
\text { satisfacción de la misma. }\end{array}$ & & & & & \\
\hline
\end{tabular}


Katz, J. L. Introduction to reference work. pp. 8-10, vol. 2.

Aunque al autor se le ha considerado como teórico, las páginas de la lectura se refieren a las funciones del Servicio de Consulta que son dadas a manera de definición, los aspectos teóricos que plantea el autor, no son considerados para su lectura y análisis.

Wheeler, J. L. Administración práctica de bibliotecas públicas. pp. 328-350.

En este apartado el autor solamente señala directrices para fundamentar la organización del departamento de consulta, no considera aspectos de carácter técnico.

Lancaster, F. Y M. J. Joncich. Evaluación y medición de los servicios bibliotecarios. pp. 85-157.

En este capítulo los autores mencionan que en 1961 la American Library Association (ALA) preparó un informe sobre el área del Servicio de Consulta, en él se distinguen los conceptos de servicio directo y servicio indirecto. El uso de estos conceptos sólo son considerados para abordar la aplicación de técnicas y evaluar los servicios de consulta, esa evaluación la orienta fundamentalmente con tipos de preguntas.

Cheney, F. N. y Weley J. M. Fundamental reference source. pp. 6-8.

Galvin, T. J. Reference souces. pp. 220-410.

El autor define el Servicio de Consulta y su desarrollo de 1800 a 1940. También explica algunos aspectos teóricos del servicio, como son los niveles en que se plantea este servicio, los autores que empezaron a proponer estos niveles a través de los conceptos conservador, moderado y liberal; explica su función en bibliotecas especializadas y menciona también a James J. Wyer destacando su trabajo sobre "la teoría del trabajo de consulta"; menciona también las funciones del bibliotecario de consulta.

Como se puede apreciar en la temática que trata la lectura se contempla la enseñanza teórica del Servicio de Consulta haciendo énfasis en los niveles del Servicio de Consulta.

Barberena Blázquez, Elvia. El Servicio de Consulta. pp. 29-35.

En 7 páginas la autora expone bree y someramente, la importancia del Servicio de Consulta, la instrucción y orientación que se debe dar al usuario, responder a preguntas específicas y evaluar los materiales de la colección, además menciona el papel que juega el bibliotecario, considerándolo de primerísima importancia en el desarrollo de la biblioteca.

Es una lectura interesante, sin embargo, no considera aspectos de carácter teórico.

\section{UNIDAD II}

\section{El bibliotecario de consulta}

La unidad II del programa de la Escuela Nacional de Biblioteconomía y Archivonomía: El bibliotecario de consulta, no tiene correspondencia con el programa de San Luis Potosí.

\section{Proposiciones Teóricas}

Se infiere que las proposiciones de carácter teórico referentes al bibliotecario de consulta se insertan en la unidad II de la ENBA, el programa de San Luis Potosí no menciona el tema. Las proposiciones a las que hacemos referencia y que se mencionan en el apartado anterior son: ser especialista en el Servicio de Consulta, implica agrupar todos aquellos elementos que existen entre el lector y la información, el bibliotecario de consulta profesional, debe estar involucrado en los quehaceres de la biblioteca y por ende de la información.

\section{Área Práctica}

No existe parte práctica en esta unidad en ninguno de los dos programas.

\section{Técnicas de Enseñanza}

En esta unidad la ENBA utiliza las técnicas de: Investigación individual y la elaboración de cuadros sinópticos. Sin embargo el programa de San Luis Potosí no plantea nada al respecto.

\section{Bibliografía}

Basilio Romero, Concepción. Metodología de consulta. pp. 36-37.

En esta lectura la autora señala las cualidades del bibliotecario en forma breve y el tiempo que se ocupará para encontrar una respuesta, no contempla aspectos teóricos.

\section{UNIDAD III}

Las obras de consulta

En esta unidad, la ENBA enmarca en los incisos "a" y "b", las obras de consulta al igual que lo hace el programa de San Luis Potosí en el inciso "a”, ambos programas tratan la definición de estos materiales y en el inciso "b" describen el tipo de obras. En este inciso, los puntos del 1 al 6 y 8 de la ENBA, tienen correlación con los puntos del 1 al 9 señalados en el programa de San Luis Potosí, ( diccionarios, enciclopedias, anuarios, bibliografías, índices, directorios, otros).

Los puntos de esta unidad que no concuerdan en ambos programas son los siguientes: la ENBA en su inciso "b" tipos, punto no. 7, trata los ATLAS, aspecto que el programa de San Luis no toca.

Cabe aclarar aquí, que del programa de San Luis Potosí fueron excluidos de la unidad III organización del departamento de consulta, inciso "b" catálogos, los puntos 5 , bibliografías y 6 . índices, en virtud de notar su repetición en la unidad IV evaluación de las obras de consulta, inciso "b" tipos, puntos 3 bibliografía, y 4, índices, respectivamente.

\section{Proposiciones Teóricas}

Para esta unidad no se identificó proposición teórica debido a que es eminentemente práctica.

\section{Área Práctica}

Ambos programas contemplan la realización de prácticas y utilizan las técnicas que se mencionan en el rubro siguiente. 


\section{Técnicas de Enseñanza}

Las técnicas utilizadas en la unidad III de la ENBA y en la unidad IV de San Luis Potosí no son coincidentes, pues mientras la ENBA utiliza "lluvia de ideas", investigación individual y elaboración de fichas bibliográficas, el programa de San Luis Potosí utiliza las técnicas de: discusión dirigida, interrogatorio y demostración.

\section{Bibliografía}

Katz, W. Introduction to reference work, pp. 13-15.

Esta lectura habla en forma general de la importancia que tiene para el Servicio de Consulta las fuentes de información y las características del servicio, así como el papel que juegan los diferentes tipos de fuentes en el ciclo de la información.

El trabajo sí contiene consideraciones teóricas, que apoyan sustancialmente la práctica.

Sabor, Josefa E. Las obras de consulta.

Esta obra provee un conocimiento sobre las fuentes generales de consulta para apoyar la tarea del referencista cumpliendo con el objetivo de que el alumno es capaz de conocer, identificar y analizar las obras de consulta. Agregando que no apoya el objetivo de evaluación de dichas obras.

Por lo tanto es fundamentalmente descriptiva y no contiene consideraciones teóricas.

\section{UNIDAD II Y III DE SAN LUIS POTOSÍ}

Información que proporciona el Servicio de Consulta

Búsqueda de información de obras de consulta.

El programa de San Luis Potosí en sus unidades Ii y III, contempla los temas de: Información que proporciona el Servicio de Consulta y búsqueda de información, los cuales no son tratados en el programa de la ENBA.

\section{Proposiciones de Enseñanza}

Las proposiciones teóricas referentes al tema de la comunicación, se ajustan a la temática tratadas en estas unidades.

\section{Área Práctica}

Respecto a este rubro, el programa de San Luis Potosí no contempla la práctica en ambas unidades.

\section{Técnicas de Enseñanza}

El programa de San Luis Potosí en su unidad II, utiliza las técnicas de discusión dirigida, interrogatorio y dramatización. Para la unidad V utiliza la técnica de demostración.

\section{Bibliografía}

Al correlacionar y analizar la literatura señalada en esta unidad, se detectó que la obra de R. Teller, hace énfasis a la ética, por lo que se considera conveniente anotar las proposiciones de carácter teórico al respecto en esta unidad.

\section{PROPOSICIONES TEÓRICAS}

En este último apartado se mencionan las proposiciones teóricas referentes a la función social y al usuario, en virtud de que no pudieron ser inferidas en ninguna de las unidades de ambos programas. Las proposiciones teóricas se especifican en el cuadro comparativo (véase página 11, 12 y 13).

\section{BIBLIOGRAFÍA SUGERIDA PARA APOYAR LOS CONTENIDOS TEÓRICOS DE LOS PROGRAMAS}

Con base en el análisis realizado de los programas, se infirió que los rubros relacionados con la comunicación, el usuario y la ética del bibliotecario de consulta, no son tratados en forma profunda desde el punto de vista teórico, por lo que convenimos en sugerir el enriquecimiento de la bibliografía que apoya los contenidos de los programas, orientados a tratar la enseñanza teórica en el Servicio de Consulta.

Es importante hacer notar que existe una rica bibliografía que trata aspectos de carácter teórico orientado al Servicio de
Consulta, sin embargo, también es importante considerar que algunos autores sólo analizan teorías existentes para dar sus puntos de vista, que en diversos casos, no aportan ideas nuevas, sino que éstas se encuentran en torno a lo que otros autores ya han dicho. Este aspecto, nos hizo reflexionar sobre las lecturas que el grupo de investigadores sugeriría para el enriquecimiento de la bibliografía básica de los programas de estudio analizados, por lo que se concluyó que se sugerirían aquellos autores que realmente aportaran conocimiento teórico sobre el tema con el fin de evitar el exceso de lecturas que posiblemente en vez de enriquecer los contenidos de los programas, entorpecieran el desarrollo de los mismos.

Otro aspecto que se tomó en cuenta para evitar la no relevancia de las lecturas recomendadas, fue el desarrollar de ellas un resumen, mismo que servirá a los maestros de la materia de consulta para que determinen si procede su lectura y análisis.

Las referencias bibliográficas que se sugieren, se presentan en orden temático y dentro de éste, en forma alfabética.

\section{COMUNICACIÓN}

GOTHBERGER, HELENA M. "Communication patterns in library reference and information service". En The library and reference service, pp. 227-241; selected by Arthur Ray Rowland. Hamden, Connecticut: The Shoe String Press, 1977.

La autora argumenta que es necesario tener presente que a fines del siglo XX, debe observarse la comunicación interpersonal como una de las bases del trabajo de consulta y que además, ésta debe basarse en la multidisciplina.

Para apoyar sus puntos de vista, la autora se fundamenta en algunos autores que han analizado las variables que se involucran en el Servicio de consulta, de entre ellos: Mount, Birdwhistell, Vavrek, Shoshid, Buber y Roger, entre otros.

NEILL, S. D. "Can be a theory of reference?" En Current trends in information: research and theory, pp. 7-19; edited by Bill Katz and Robin Kinder. New York: The Howorth Press, 1987. 
El autor a partir de una serie de preguntas sobre la existencia de la teoría en el Servicio de Consulta, presenta sus reflexiones con base en diversos autores que han analizado este tema.

Los temas que aborda son: el proceso de la consulta, la finalidad de la teoría, el desarrollo de la teoría, algunos ejemplos de teorías sobre la memoria, y el uso de teorías. Sus puntos de vista sobre las temáticas señaladas los apoya en Benson, Maloney, Taylor y Dervin.

El análisis que hace sobre las teorías de la comunicación los centra en los modelos creados por Retting, Dervin, Shanon y Weaver.

RETTING, JAMES. "A theoretical model and definition of the reference process". En Reference Quaterly, 18(1) 19-29, 1978.

Bajo el título un modelo teórico y definitorio de los procesos de consulta, el autor analiza algunos paradigmas y supuestos teóricos de diversos autores que han incursionado en la investigación teórica del Servicio de consulta, de los autores citados se destacan los siguientes: Butter, Rothstein, Wyer, Rag, McClure, Whittaker. Rees, Vavrek, Shannon y Schramm.

Quizá el valor mayor del artículo consiste en que Retting analiza y explica el modelo Vavrek sobre el proceso de la consulta orientado a la comunicación, las variables base que se distinguen en ese modelo son: $\mathbf{A}=$ usuario, $\mathbf{B}=$ bibliotecario, $\mathbf{C}=$ fuentes de información, $\mathbf{X}=$ pregunta, $\mathbf{X} \mathbf{1}=$ retroalimentación, $\mathbf{Y}=$ mensaje, $\mathbf{Z}=$ mensaje bibliotecario-fuentes de información $\mathbf{z} \mathbf{1}=$ retroalimentación (correlación con $\mathbf{Z}$ ), $\mathbf{n}=$ número de variables.

El modelo enfatiza la comunicación interpersonal como la base del proceso de referencia.

STANOULOV, NICOLAY. "Contemporary trends in applied metatheoretic research: A case study about information metatheory : a Fragment". En Current trends in information : research and theory, pp. 199-210; edited by Bill Katz and Robin Kinder. New York : The Howorth Press, 1987.
El autor propone el uso de una metateoría, esto es, una teoría de teorías, sus puntos de vista, los fundamentos en la utilización de una serie de ecuaciones matemáticas que permiten según él, medir el comportamiento de diversas variables involucradas en el manejo y recuperación de información, esto incluye a la comunicación.

Aunque el autor generaliza esta metateoría al manejo y recuperación de información, creemos que también sería aplicable al Servicio de Consulta.

\section{ÉTICA DEL BIBLIOTECARIO DE CONSULTA}

Ethics and reference services. New York : Haworth Pess, 1982. 173 p.

Esta obra es una antología sobre aspectos relacionados con la ética en el contexto del Servicio de Consulta; la temática relacionada con ética e interacción del bibliotecario con los usuarios; la ética y la información, son tratados en forma clara e interesante.

Al final de cada trabajo contemplado en esta antología, los autores proponen, una rica bibliografía relacionada con el tema.

\section{FUNCIÓN SOCIAL DEL SERVICIO DE CONSULTA}

Libraries in society, London : Clive Bingley, 1978, p. 27-38 y p. 70-77.

Esta obra consiste en una compilación de trabajos de varios autores de diversas corrientes políticas, mismos que hacen su análisis de las bibliotecas desde el punto de vista social, la temática contempla: función social, educativa, el usuario, la comunidad, su fenomenología y la cultura.

Creemos que esta obra es de gran ayuda para esclarecer el debate que se da entre los objetos individuales y sociedad.

\section{USUARIO}

COLLINSON ROBERT L. Library asístanse to readers. London: C. Lockwood, 1965, 139 p.

Esta obra presenta una serie de aspectos relativos a la asistencia de los lectores a través del Servicio de Consulta, utiliza para ello: la promoción de la biblioteca; la elaboración de guías o manuales de los servicios, la utilización de las obras de consulta para proporcionar una asistencia al lector. Esta obra hace énfasis sobre la instrucción de usuarios.

KATZ, WILLIAM A. "The user and non user of reference service". En Introduction to reference work. pp. 35-36, New York : Mc Graw Hill, 1974. vol. 2.

En esta parte, el autor habla sobre el usuario del Servicio de Consulta, lo divide en dos categorías, usuarios y no usuarios del Servicio de Consulta, se explica con amplitud, cuál es la diferencia entre estas categorías, indicando que el usuario es aquél que presenta necesidades "especiales" de información como puede ser un investigador, un especialista, o un estudiante. El no usuario lo ubica en trabajadores, hombres y mujeres "comunes", en esta categoría también incluye a las clases desprotegidas (pobres, no anglosajones, etc.).

No habla acerca de la relación entre lo político y lo filosófico, asume que estos dos conceptos no pueden ser aislados y más aún en lo concerniente al Servicio de Consulta.

El autor enfatiza los niveles del Servicio de Consulta y asevera que pocas bibliotecas se ciñen a un solo nivel.

SHERA A., JESÉ H. The foundations of educational librarianship. New York : Wiley-Becker, 1972. 511 p.

La obra nos presenta los fundamentos que se deben de tomar en cuenta para la educación bibliotecológica, parte de lo que es la comunicación como base principal, así como también su relación con la sociedad, la cultura y la biblioteca, pero tomando a la comunicación interrelacionada con la psicología, la fisiología y la sociología.

Desarrolla la necesidad de una fundamentación epistemológica de la ciencia bibliotecaria, ligándola con la naturaleza del conocimiento, su aspecto social y la función que tiene la biblioteca.

Presenta a la biblioteca y al bibliotecario como productos de la comunicación del conocimiento dentro de un proceso social, así como también particulariza sobre la diseminación selectiva de informa- 
ción, intentando ir hacia la unificación de una teoría bibliotecológica.

Por último el autor presenta una propuesta para un plan de estudio a nivel profesional y de posgrado.

SHERA, JESÉ H. Libraries and organization of knowledge. London C. Lockwood, 1966. pp. 12-17.

El capítulo del libro nos habla sobre las bases epistemológicas de la bibliotecología; nos hace referencia a que el ser humano es el único que manifiesta necesidades de información y esto lo hace a través de su cerebro el cual ha tenido una larga evolución biológica para llegar a su estado actual.

Con la necesidad de información surge la comunicación oral y la escrita en la cual tiene su relación la bibliotecología como disciplina, por lo cual surge entonces una disciplina que se encarga del estudio de la satisfacción de necesidades de información y que a su vez genera el mismo ser humano.

JAHODA, GERALD Y JUDITH SCHICK BRAUNAGEL. The librarian and reference queries : a systematic approaches. New York : Academic, 1980, $175 \mathrm{p}$.

La obra nos presenta el concepto del Servicio de consulta así como su modelo.

El enfoque de la obra nos indica cómo hacer la interpretación de la pregunta, la respuesta, así como de realizar las búsquedas de información para satisfacer las necesidades de información del usuario. Trata sobre las técnicas de comunicación y de la entrevista, habla sobre la comunicación no verbal, así como de las búsquedas en línea en bancos de datos bibliográficos para poder satisfacer las necesidades de información de los usuarios.

FOSKETT D. J. Science humanism and libraries, London : C. lokwood, 1964, pp. 45-56, 123-142.

Los capítulos seleccionados de esta obra presentan las necesidades de información o conocimiento que tienen los diferentes usuarios que asisten a los diversos tipos de bibliotecas (públicas, especializadas, etc.) y en especial en las bibliotecas de industrias.

Menciona la relación estrecha entre el Servicio de Consulta y otras de las actividades profesionales de la biblioteca como son: la catalogación y la clasificación; ambas actividades son vistas como la base para proporcionar la información que necesita el usuario, ya que si se encuentran ambas bien realizadas el Servicio de Consulta funcionará eficientemente.

\section{CONCLUSIONES}

abEn los contenidos de los programas, no se encontró en forma detallada o explícita la enseñanza de las bases teóricas del Servicio de Consulta, aspecto que permite comprobar nuestra hipótesis de trabajo.

abSe puede deducir que en algunas unidades de ambos programas, se perfila la enseñanza de determinadas bases teóricas.

abSólo son dos las referencias bibliográficas que utilizan en el programa de SLP que contienen aspectos teóricos sobre el
Servicio de Consulta, por lo que se infiere que la enseñanza teórica de este servicio, es muy limitada.

abAmbos programas contemplan a Katz, autor que trata aspectos teóricos, sin embargo las partes que se seleccionan para su estudio en ambos programas, creemos, no son las relevantes sobre la teoría en el Servicio de Consulta.

abAmbos programas utilizan diferente bibliografía a excepción de una referencia (Katz, Introduction to reference work).

Creemos que si se utilizara la misma bibliografía, se podría apoyar la homogeneidad de la enseñanza, lo que repercutiría en la enseñanza de conocimientos básicos comunes.

abLas técnicas de enseñanza aprendizaje, sólo coinciden en dos: discusión dirigida e interrogatorio. Creemos que haría falta la utilización de prácticas orientadas a las unidades donde se infiere, se dan las proposiciones teóricas.

abLa técnica de dramatización utilizada en el programa de SLP nos hace suponer que se contemplan sólo a nivel práctico los aspectos de la comunicación bibliotecario-usuario.

abCon base en los contenidos de ambos programas concluimos que la orientación de los mismos son eminentemente prácticos.

abLas proposiciones teóricas que se infieren a la función social y al usuario, no aparecen en forma específica en los contenidos de ambos programas, por lo que deducimos que estos puntos teóricos no son tratados.

\section{CITAS BIBLIOGRÁFICAS}

1. BUNGE, Charles A. "Metateoría" p. 227, En El pensamiento científico, conceptos, avances, métodos. México : Tecnos-UNESCO, 1983.

2. FERRATER MORA, José. Diccionario de Filosofía. México : Alianza Editorial, 1980. p. 3221-3222, vol. 4 


\section{BIBLIOGRAFÍA CONSULTADA}

AMERICAN LIBRARY ASSOCIATION, World enciclopedia of library and information service. $2^{\text {nd }}$. ed. Chicago, ALA, 1986, pp. 692-697.

BAR-HELLEL, T., Bunge, A. Mostowski y otros. El pensamiento científico: conceptos, avances, métodos. México, REI, 1977.

BUCKLAND, Michael K. Library service in theory and context. $2^{\text {nd }}$. ed. Oxford, Pergamon Press, 1988, 250 p.

BUNGE, Charles A. The personal touch: a briet overview of the development of reference services in American Libraries. En: Lee, Sul Ho. Reference Service: a perspectiver. U.S. The Pierian Press, 1983. po. 1-15.

COLLINSON, Robert L. Library assistance to readers. London: C. Locwood, 1965, 139 p.

DAVINSON, Donald. Reference service. London, Clive Bingley, 1980. pp. 5-27.

FAIBISOFF, Silvya G. and Donald Ely. "Information and information needs". pp. 2-16. En Information reports and bibliographics. Vol. 5, no. 5, 1976.

FOSKETT, D. J. Science humanism and libraries. London : C. Locwood, 1964, $150 \mathrm{p}$.

GROGAN, Denis. Practical reference work. London, Bingley, 1979, 144 p. (Autline of Modern Librarianship)

JAHODA, Gerald and Judith Schick Braunagel. The libraries and reference queries : a systematic approach. New York : academic, 1980. 175 p.

KATZ, Bill y Ruth A. Fraley, ed. Ethics and reference service. New York, The Haworth Press, 1982, 173 p. (The Reference Librarian Number 4)

-ed. International aspects of reference and information services. New York, The Haworth Press, 1987, 243 p.

-ed. Reference services today from interview to Burnout, New York, The Haworth Press, 1987, 312 p. (The Reference Librarian Number 16)

MORALES Campos, Estela. El servicio de consulta. México : CUIB, 1985.

NIELSEN, Brian. "Teacher of intermediary: alternative profesional models in the information age". En: College and research Libraries. Vol. 43, no. 3, 1982:183-191.

PERALES Ojeda, Alicia. Las obras de consulta, reseña histórica-crítica. México: UNAM, 1962. 373 p.

RETTING, James. "A theoretical model and definition of the reference process", En : $R Q$ vol. 18, no. 1978:19-29.

ROWLAND, Arthur Ray, comp. The librarian and reference service. Hamde, Connecticutm The String, Press Inc. 1977, 281 p. 
SABLE, Martin H. "Teaching reference by the Smorgasbord method". En : International Library Review. Vol. 16, no. 3, 1984:271-283.

"Sustantive factors for a theory of reference service". En: International Library Review, vol. 4, no. 4, 1984:407-414.

SHERA, Jesse H. The foundation of educational librarianship. New York : Wiley-Becker, 1972, 522 p.

-Libraries and the organization of knowledge. London : Locwood, 1966, $230 \mathrm{p}$.

SHORES, L. y Krzys R. "Reference books". En : Encyclopedia of library and information science. New York : Marcel Dekker, 1972. vol. 25, pp. 152-197.

VAVREK, Bernard F. "A theory of reference service”. En: College and Research Libraries, vol. 86, no. 6, 1968:508-510.

WHITTAKER, Kenneth. "Towqrds a theory for reference and information services”. En: Journal of Librarianchip, vol. 9 no. 1, 1977: 49-63. 


\title{
ANEXO 1
}

\section{Programa de la materia de Servicio de Consulta de la Universidad Autónoma de San Luis Potosí}

\section{LICENCIATURA EN BIBLIOTECONOMIA}

\author{
Fundamentos del Servicio de Consulta
}

\section{Presentación del curso}

\section{Objetivos Generales}

Al término del curso, el alumno será capaz de:

1. Explicar en qué consiste el Servicio de Consulta.

2. Identificar los tipos de preguntas en consulta.

3. Describir la organización del Departamento (Sección, etc.) de Consulta.

4. Evaluar el material de consulta. 5. Realizar búsquedas de información previamente solicitada.

\section{Contenido}

\section{El Servicio de Consulta}

II. Información que proporciona el Servicio de Consulta.

III. Organización del Departamento (Sección, etc.) de Consulta.

IV. Evaluación de material de consulta.

V. Búsqueda de información en obras de consulta.

\section{Metodología}

1. Los estudiantes recibirán el primer día de clases, la presentación del curso y a lo largo del mismo, el contenido programático de cada unidad por desarrollar, con la indicación bibliográfica para su preparación.

2. Para preparar cada unidad, el alumno deberá:

- Revisar el temario y la bibliografía. - Hacer las lecturas básicas que se indiquen.

- Tomar y ordenar notas que le faciliten la exposición en clase.
- Elaborar las prácticas de laboratorio que se indiquen.

3. El alumno deberá participar en clase tomando como base principal sus resúmenes.

4. Solo se permitirá utilizar los resúmenes a lo largo de cada sesión.

5. Al término de cada sesión, el alumno entregará sus notas a fin de que sean revisadas.

6 . Los resúmenes y prácticas de laboratorio no se recibirán después de la fecha indicada para su entrega. 7. Las fechas de exámenes serán dadas con anticipación a los alum. nos.

\section{Evaluación}

La evaluación final del curso se determinará de acuerdo a los siguientes porcentajes.

Ejercicios (Resúmenes y prácticas de laboratorio) $30 \%$

Participación y asistencia 5\% Exámenes parciales $65 \%$

Requisitos para:1.Examen Extraordinario: Además del examen, el alumno presentará todos sus ejercicios corregidos y en limpio.

2. Examen a título de suficiencia:Además del examen y los ejercicios corregidos y en limpio, el alumno presentará una investigación, cuyo tema será dado con anticipación por el profesor.

\section{Bibliografía}

ANDERS, M. "El Servicio de Consulta en las Bibliotecas Especiales" En Bibliotecas y Archivos. 1:67-69 1970 .
BARBERENA BLAZQUEZ, E. "El Servicio de Consulta" En Bibliotecas y Archivos. 1:29-35 1967.

CHENEY, F. N y Wileey, J.W. Fundamental reference sources. 2 nd Ed. Chicago, ALA, 1980. p. 68.

DAVINSON, D. Reference service. London, Clive Bingley, 1979. $235 \mathrm{p}$.

FOSKETT, D.J. Information service in libraries. Hamden, Archon Books, 1970. p. 79-92.

FREIBAND, S.J. "El servicio de referencia en las bibliotecas universitarias de Colombia" En Boletín de la Unesco para las Bibliotecas 32(2):98-101.

GALVIN, T.J. Current problems in reference service. New York, Bowker, 1971. $162 \mathrm{p}$.

- ----"Reference services in libraries" En Encyclopedia of library and information science. New York, Marcel Dekker, 1972. v. 25, p. $210-220$.

GOUDL, G.N. y WOLFE, I. C. How to organized and maintain the libran picture/pam PHLET file. New York, Oceano Pub., 1968. p. 1-7, 21-25, 84-92.

JAHODA, G. y Braunagel, J.S. The librarian and reference queries; $a$ systematic approach. New York, Academic Press, 1980. 175 p.

KATTZ, W.A. Introduction to reference work. 3rd. ed. New York, McGraw-Hill, 1978. $2 \mathrm{v}$.

KRAMER, G. Notas bibliotecológicas. 2a. ed. México, Pax-México, 1972. $380 \mathrm{p}$
LITTON, G. La información en la biblioteca moderna. Buenos $\mathrm{Ai}$ res, Bowker, 1971, 189 p

LOCK, R.N. "The reference library" En Library Administration. New York, Philosophical Library, 1962. p. $36-46$.

ORSINI, L.K. "Reference service to children; past, presente and future" En Advance in librarians hip. New York, Seminar Press, 1970, vol. 1, p. 159-170

PERALESOJEDA, A Lasobras de consulta; reseña histórico- crítica. México, UNAM, 1962.373p.

SABOR, J.E. "El servicio de referencia" En ALBANI, J. et. al. Manual de Bibliotecologia para bibliotecas populares. Buenos Aires, Kapeluz 1951. p. 189-212.

SANDHU, S.S. "Misión del bibliotecario referencista especializado en la biblioteca universitaria" En Boletín de la Unesco para las bibliotecas. 29(2):69-73 1975 .

SHORES, L y KRZYS, R. "Reference books" En Encyclopedia of library and information science. Marcel Dekker, 1972. v. 25, p. 152-197.

TELLER, R. "Ethical consierations in the question negotiation cycle" En The reference librarian. 10(4):133-141 1982.

THOMAS, D.M., HINCLEY, E y EISENBAC, R. The effective reference librarian. New York, Academic Press, 1981. 213 p.

WYNAR, B.S. Reference book in paperback; an annotated guide. Littleton, Libraries Unlimited. 1976. $317 \mathrm{p}$

\section{UNIDAD I}

Objetivos Particulares

1. Explicar la historia del Servicio de Consulta.

2. Definir el Servicio de Consulta.

3. Analizar los objetivos del Servicio de Consulta.

4. Identificar las características de Servicio de Consulta.

\section{EL SERVICIO DE CONSULTA}

\section{Cisntenido}

A. El Servicio cie Consulta.

1. Historia

2. Definición

3. Objetivos

4. Características

Técnicas

1. Discusión dirigida
2. Interrogatorio

Material visual

\section{Recursos}

\section{Bibliografía}

CHENEY, F.N. y WILEY, J.M Fundamental reference sources. 2nd. ed. Chicago, ALA 1980. p. 6-8.
GALVIN, T.J. "Reference services and libraries" En Encyclopedio of library and information science. New York, Marcel Dekker, 1972. v. 25 , p. $410-220$. 


\section{UNIDAD II}

\section{INFORMACION QUE PROPORCIONA EL SERVICIO DE CONSULTA}

\begin{abstract}
Objetivos Partic alares 1. Identificar los tipos de preguntas que debe responder el Servicio de Consulta.

2. Descubrir los problemas de comunicación entre el bibliotecario yel usuario.

3. Analizar los factores que influyen en la respuesta que se da al usuario.
\end{abstract}

\begin{tabular}{|c|c|c|c|}
\hline $\begin{array}{l}\text { Objetivos Particulares } \\
\text { 1. Explicar las funciones que se re- } \\
\text { alizan en el Departamento de Con- } \\
\text { sulta. }\end{array}$ & $\begin{array}{l}\text { B. Catálogos } \\
\text { 1. Editoriales } \\
\text { 2. Servicios al Público } \\
\text { 3. Colectivos }\end{array}$ & $\begin{array}{l}\text { Recursos } \\
\text { Material visual } \\
\text { Bibliografia }\end{array}$ & $\begin{array}{l}\text { GALVIN, T.J. "Reference services } \\
\text { and libraries" En Encyclopedia } \\
\text { of library and information } \\
\text { science. New York, Marcel } \\
\text { Dekker, 1972. v. 25, p. } 220-221 .\end{array}$ \\
\hline $\begin{array}{l}\text { 2. Identificar los catálogos que ela- } \\
\text { bora y los que utiliza el Departamen- } \\
\text { to de Consulta. } \\
\text { Contenido }\end{array}$ & $\begin{array}{l}\text { 4. Archivo Vertical } \\
\text { 5. Bibliografías } \\
\text { 6. Indices } \\
\text { Técnicas }\end{array}$ & $\begin{array}{l}\text { BARBERENA BLAZQUEZ, E. } \\
\text { "El Servicio de Consulta" En } \\
\text { Bibliotecas y Archivos. (1): } 29 . \\
351967 .\end{array}$ & $\begin{array}{l}\text { GOULD, G.N. y WOLFE, I.C. How } \\
\text { to organize and maintain the li- } \\
\text { brary picture/pamphlet file. } \\
\text { New York, Oceano Pub., } 1968 . \\
\text { p. } 1-7,21-25,84-92 \text {. }\end{array}$ \\
\hline $\begin{array}{l}\text { A. Funciones del Departamento de } \\
\text { Consulta. }\end{array}$ & $\begin{array}{l}\text { 1. Discusión dirigida } \\
\text { 2. Interrogatorio }\end{array}$ & & \\
\hline
\end{tabular}

Objetivos Particulares

1. Definir en que consisten las obras de consulta.

2. Realizar el tipo de material utilizado en consulta.

3. Evaluar las obras de consulta.

\section{Contenido}

A. Obras de consulta

1. Definición

2. Características

B. Material específico de consulta

1. Enciclopedias
A. Tipos de preguntas.

1. Orientación

2. Respuesta concreta y rápida

3. Investigación bibliográfica

B. Entrevista bibliotecario-usuario

C. Características de una respuesta

Técnicas

\section{Contenido} adecuada
1. Discusión dirigida

2. Interrogatorio

3. Dramatizació!।

\section{Recursos}

Material visual

\section{Bibliografia}

FOSKETT, D. J. Information service in libraries. Handen, Archon Books, 1970. p. 79-92.

\section{UNIDAD III}

\section{ORGANIZACION DEL DEPARTAMENTO DE CONSULTA}

\section{UNIDAD IV}

\section{EVALUACION DEL MATERIAL DE CONSULTA}

a. Definición
b. Características
2. Diccionarios
a. Definición
b. Características
3. Indices
a. Definición
b. Características
4. Bibliografías
a. Definición
b. Características
5. Almanaques, anuarios y directo-
rios

b. Característica

6. Resúmenes

a. Definición

b. Características

7. Biografías

a. Definición

b. Características

8. Publicaciones Oficiales

a. Definición

b. Características

9. Microformatos

a. Definición

b. Características

KATZ, W. A. Introducrion to refernce work; reference service and reference processes 3 rd. ed. New York, McGraw-Hill, 1978. v. 2, p. $61-79,81-119$

TELLER, R. "Ethical consideration in the question negotiation cycle" En The reference librarian; 10(4) :133-141 1982.
Técnicas

1. Discusión dirigida

2. Interrogatorio

\section{Recurso}

Material visua

$$
\text { Bibliografía }
$$

SHORES, L y Krzys, R "Reference brary and Information Science. New York, Marce Dekker, 1972, V. 25, 0. 152-197.
3. Demostración books" En Encyclopedia of Li-

\section{UNIDAD V}

Objetivo Particular

Proporcionar las respuestas a preguntas previamente solicitadas.

\section{Contenido}

\section{BUSOUEDA DE INFORMACION EN OBRAS DE CONSULTA}

\begin{tabular}{l|l} 
A. Describir el material y encabeza- & 2. La ficha bibliográfica
\end{tabular} mientos utilizados para encontrar la 3 . Biblioteca o Archivo donde se lorespuesta.

B. Proporcionar como respuesta a las preguntas: 1. La signatura topográfica calice la información.

\section{Técnica}

Demostración

\section{Recurso}

Material documental

Fuentes

Bibliotecas, archivos y librerías. 


\section{Anexo 2}

\section{Programa de la materia de Servicio de Consulta de la Escuela Nacional de Biblioteconomía y Archivonomía}

\begin{tabular}{|c|c|c|c|c|c|c|}
\hline \multirow[t]{2}{*}{ 1. MATERIA: SERVICIO DE CONSULTA } & \multirow[t]{2}{*}{ 2. CLAVE: 0207} & \multirow[t]{2}{*}{ 3. SERIACION: } & 4. H.T. & H.P. & T.H.S. & C.R. \\
\hline & & & 2 & 2 & 4 & 6 \\
\hline
\end{tabular}

\begin{tabular}{|c|c|c|c|c|c|}
\hline $\begin{array}{l}\text { 6. TIEMPO } \\
\text { ESTIMADO } \\
\text { (en HRS) }\end{array}$ & $\begin{array}{l}\text { 7.- OBJETIVO } \\
\text { ESPECIFICO } \\
\text { (Por unidad) }\end{array}$ & $\begin{array}{l}\text { 8. CONTENIDOS } \\
\text { PRINCIPALES } \\
\text { (por unidad) }\end{array}$ & $\begin{array}{l}\text { 9. ACTIVIDADES DE } \\
\text { APRENDIZAJE }\end{array}$ & 10. BIBLIOGRAFIA. & $\begin{array}{l}\text { 11. EVALUACION } \\
\text { (por curso) }\end{array}$ \\
\hline 4 & $\begin{array}{l}\text { El alumno } \\
\text { identificará cuál es la } \\
\text { ubicación del } \\
\text { departamento de } \\
\text { consulta dentro de la } \\
\text { biblioteca, cuáles } \\
\text { son los elementos } \\
\text { que lo componen, la } \\
\text { importancia de las } \\
\text { relaciones con otros } \\
\text { departamentos y sus } \\
\text { funciones. }\end{array}$ & $\begin{array}{l}\text { UNIDADI } \\
\text { EL DEPARTAMENTO } \\
\text { DE CONSULTA. } \\
\text { a) Ubicación dentro } \\
\text { de la biblioteca. } \\
\text { b) Elementos que } \\
\text { integran } \\
\text { departamento } \\
\text { c) Relación con otros } \\
\text { departamentos } \\
\text { d) Funciones deI } \\
\text { servicio de consulta. }\end{array}$ & $\begin{array}{l}\text { Plática informal dirigida } \\
\text { por el docente para } \\
\text { detectar el nivel de } \\
\text { conocimiento del } \\
\text { alumnado. } \\
\text { Previa lectura del tema, el } \\
\text { educando y el docente } \\
\text { analizarán los tópicos que } \\
\text { componen la unidad. } \\
\text { Los alumnos elaborarán } \\
\text { cuadros sinópticos sobre } \\
\text { lo analizado. } \\
\text { Elaboración de la memoria } \\
\text { de la primera unidad. } \\
\text { Investigación individual } \\
\text { sobre las cualidades y } \\
\text { preparación de } \\
\text { bibliotecario de consulta. }\end{array}$ & $\begin{array}{l}\text { Pizarrón, gis y borrador. } \\
\text { Planos de la biblioteca en donde } \\
\text { labora el alumno } \\
\text {-Cuadros sinópticos elaborados } \\
\text { por el docente } \\
\text { - Basilio, C. Metodología de la } \\
\text { consulta. En Ciencia } \\
\text { bibliotecaria. v. 2. núm. } 1 \text { p. } 29 \text { - } \\
32 \text {. } \\
\text {-Wheeler, J.L. Administración } \\
\text { práctica de bibliotecas públicas. } \\
\text { pag. 328-350. } \\
\text {-Katz, W. Introduction to } \\
\text { reference work. p. 8-10 } \\
\text {-Lancaster,F. Evaluación y } \\
\text { medición de los servicios } \\
\text { bibliotecarios. p. } 85-157 \text {. }\end{array}$ & $\begin{array}{l}\text { Participación } \\
\text { individual } \\
\text { Entregar Memoria de } \\
\text { la primera unidad. } \\
\text { Aplicación del primer } \\
\text { examen parcial en } \\
\text { forma individual } \\
\text { escrito. }\end{array}$ \\
\hline \multicolumn{5}{|c|}{ 12. El director. } & - \\
\hline $\begin{array}{l}\text { 6. TIEMPO } \\
\text { ESTIMADO } \\
\text { (en HRS) }\end{array}$ & $\begin{array}{l}\text { 7.- OBJETIVO } \\
\text { ESPECIFICO } \\
\text { (Por unidad) }\end{array}$ & $\begin{array}{l}\text { 8. CONTENIDOS } \\
\text { PRINCIPALES } \\
\text { (por unidad) }\end{array}$ & $\begin{array}{l}\text { 9. ACTIVIDADES DE } \\
\text { APRENDIZAJE }\end{array}$ & 10. BIBLIOGRAFIA. & $\begin{array}{l}\text { 11. EVALUACION } \\
\text { (por curso) }\end{array}$ \\
\hline 8 & $\begin{array}{lr}\text { Al término de la } \\
\text { unidad el alumno } \\
\text { será capaz de } \\
\text { adquirir } & \text { los } \\
\text { conocimientos } \\
\text { básicos r para } \\
\text { desempeñar } & \text { el } \\
\text { puesto } & \text { de } \\
\text { bibliotecario } & \text { de } \\
\text { consulta. } & \end{array}$ & $\begin{array}{l}\text { UNIDAD I } \\
\text { EL BIBLIOTECARIO } \\
\text { DE CONSULTA } \\
\text { a) Preparación } \\
\text { b) Cualidades } \\
\end{array}$ & $\begin{array}{l}\text { Los alumnos elaborarán } \\
\text { los cuadros sinópticos y } \\
\text { sobre la preparación y } \\
\text { cualidades del } \\
\text { bibliotecario de consulta. }\end{array}$ & $\begin{array}{l}\text { Pizarrón, gis, borrador. } \\
\text { Cuadros sinópticos elaborados } \\
\text { en clase por los alumnos y el } \\
\text { docente. } \\
\text {-Basilio, C. "Metodología de } \\
\text { consulta". En Ciencia } \\
\text { bibliotecaria. v. 2. núm. 1. pág. } \\
29,36-37 \text {. } \\
\text {-Wheeler, J. L. Administración } \\
\text { práctica de bibliotecas públicas } \\
\text { p. } 334-340 . \\
\text {-Petru, W. Técnicas del } \\
\text { bibliotecario. }\end{array}$ & $\begin{array}{l}\text { Participación } \\
\text { individual } \\
\text { Entrega de trabajos } \\
\text { de investigación, } \\
\text { e a I u a n d o } \\
\text { contenido. } \\
\text { Aplicación del } \\
\text { segundo examen } \\
\text { parcial en forma } \\
\text { individual }\end{array}$ \\
\hline
\end{tabular}




\begin{tabular}{|c|c|c|c|c|c|}
\hline $\begin{array}{l}\text { 6. TIEMPO } \\
\text { ESTIMADO } \\
\text { (en HRS) }\end{array}$ & $\begin{array}{l}\text { 7.- OBJETIVO } \\
\text { ESPECIFICO } \\
\text { (Por unidad) }\end{array}$ & $\begin{array}{l}\text { 8. CONTENIDOS } \\
\text { PRINCIPALES } \\
\text { (por unidad) }\end{array}$ & $\begin{array}{l}\text { 9. ACTIVIDADES DE } \\
\text { APRENDIZAJE }\end{array}$ & 10 BIBLIOGRAFIA. & $\begin{array}{l}\text { 11. EVALUACION } \\
\text { (jor curso) }\end{array}$ \\
\hline 48 & $\begin{array}{l}\text { El alumno } \\
\text { identificaná cuáles } \\
\text { son las obras de } \\
\text { consulta y conocerá } \\
\text { los pasos a seguir } \\
\text { para su analisis. } \\
\text { Elalumno serácapaz } \\
\text { de evaluar los } \\
\text { diccionatios y } \\
\text { enciclopedas. }\end{array}$ & $\begin{array}{l}\text { UNIDAD III } \\
\text { LAS OBRAS DE } \\
\text { CONSULTA } \\
\text { a) Definición } \\
\text { b) Tipos } \\
\text { b.1) Diccionarios } \\
\text { b.2) Enciciopedias } \\
\text { b.3) Anuarios } \\
\text { b.4) Bibliografia } \\
\text { b.5) Indices } \\
\text { b.6) Directorios } \\
\text { b.7) Atias } \\
\text { b.8) Otras } \\
\text { c) Análisis de obras } \\
\text { de consulta } \\
\text { d) Evaluación de } \\
\text { Diccionarios y } \\
\text { Enciclopedias }\end{array}$ & $\begin{array}{l}\text { Lluvias de ideas sobre } \\
\text { obras de consulta. } \\
\text { Investigación individual } \\
\text { sobre las caracteristicas y } \\
\text { utilidad de las obras de } \\
\text { consulta. } \\
\text { El alumno elaborara fichas } \\
\text { bibliográficas sobre obras } \\
\text { de consulta para } \\
\text { determinar su arreglo y } \\
\text { contenido. } \\
\text { El alumno investigará } \\
\text { sobre los aspectos a tomar } \\
\text { en cuenta para evaluar } \\
\text { obras de consulta. } \\
\text { El alumno evaluara obras } \\
\text { de consulta generales } \\
\text { (enciclopedias y } \\
\text { diccionarios) }\end{array}$ & $\begin{array}{l}\text { Pizarión, gis, borrador. } \\
\text {-Katz, W. Introduccion to } \\
\text { reference work. p. 13-15 } \\
\text {-Perales, A. Las obras de } \\
\text { consulta } \\
\text {-Sabor, Josefa E. Manual de } \\
\text { fuentos de información }\end{array}$ & $\begin{array}{l}\text { Participación } \\
\text { individual } \\
\text { Entrega de trabajos } \\
\text { de investigación } \\
\text { evaluando contenido } \\
\text { Entrega de análisis y } \\
\text { evaluación de obras } \\
\text { de consulta. } \\
\text { Entrega de memoria } \\
\text { de las unidades il yill } \\
\text { Aplicación del } \\
\text { examen final en } \\
\text { forma individual, } \\
\text { escrito. }\end{array}$ \\
\hline
\end{tabular}

\section{SERVICIO DE CONSULTA}

Para acreditar el curso de Servicio de Consulta, el alumno deberá obtener los porcentajes que a continuación se enuncian.

\begin{tabular}{|l|l|l|}
\hline & Participación individual & $10 \%$ \\
\hline & Entrega de trabajos de investigación & $10 \%$ \\
\hline & Entrega de la Memoria. 1a. Unidad. & $10 \%$ \\
\hline Evaluaciones: & Eer. examen parcial & $10 \%$ \\
\hline & Entrega de análisis y evaluación de obras de consulta & $10 \%$ \\
\hline 2do. examen parcial & $10 \%$ \\
\hline & Entrega de la memoria del curso & $20 \%$ \\
\hline & Examen final & $20 \%$ \\
\hline & Total & $100 \%$ \\
\hline
\end{tabular}

NOTA: estos porcentajes son los máximos a obtener. 